Supplement of SOIL, 5, 15-32, 2019

https://doi.org/10.5194/soil-5-15-2019-supplement

(C) Author(s) 2019. This work is distributed under

the Creative Commons Attribution 4.0 License.

(c) (1)

Supplement of

\title{
Global meta-analysis of the relationship between soil organic matter and crop yields
}

Emily E. Oldfield et al.

Correspondence to: Emily E. Oldfield (emily.oldfield@yale.edu)

The copyright of individual parts of the supplement might differ from the CC BY 4.0 License. 
Table S1: Summary statistics for our dataset.

\begin{tabular}{lcc} 
Model Variable & Mean & Range \\
\hline SOC $(\%)$ & 1.13 & $0.09-3.73$ \\
$\mathrm{~N}$ input $\left(\mathrm{kg} \mathrm{N} \mathrm{ha}^{-1}\right.$ year $\left.^{-1}\right)$ & 118 & $0-570$ \\
$\mathrm{pH}$ & 7.15 & $3.20-9.19$ \\
Aridity & 0.76 & $0.11-2.01$ \\
Latitude $\left(^{\circ}\right)$ & 30.49 & $-37.9-56.3$ \\
$\%$ Clay & 26.32 & $3.7-72.0$ \\
\hline Number of data points with maize & 380 \\
Number of data points with wheat & 454 \\
Number of data points receiving irrigation & 377 \\
\hline
\end{tabular}


Table S2: Modeled regression coefficients with standard errors, standardized

coefficients, and $\boldsymbol{P}$ values when excluding observations from $C h i n a$ and when

analyzing observations from China only.

Excluding China

\begin{tabular}{|c|c|c|c|c|c|c|}
\hline Variable & $\begin{array}{c}\text { Unstandardized } \\
\text { Coefficients }\end{array}$ & $\begin{array}{l}\text { Standardized } \\
\text { Coefficients }\end{array}$ & $P$ value & $\begin{array}{c}\text { Unstandardized } \\
\text { Coefficients }\end{array}$ & $\begin{array}{c}\text { Standardized } \\
\text { Coefficients }\end{array}$ & $P$ value \\
\hline Intercept & $-5.65 \pm 1.81$ & $4.93 \pm 0.22$ & $<0.00001$ & $7.89 \pm 5.40$ & $5.92 \pm 0.31$ & $<0.00001$ \\
\hline SOC & $0.69 \pm 0.64$ & $0.34 \pm 0.39$ & 0.38 & $4.45 \pm 1.24$ & $2.57 \pm 0.38$ & $<0.00001$ \\
\hline $\mathrm{SOC}^{2}$ & $-0.29 \pm 0.19$ & $-0.58 \pm 0.38$ & 0.12 & $-0.57 \pm 0.43$ & $-0.38 \pm 0.29$ & 0.19 \\
\hline $\mathrm{N}$ input & $0.019 \pm 0.0018$ & $2.58 \pm 0.17$ & $<0.00001$ & $0.017 \pm 0.0022$ & $1.58 \pm 0.22$ & $<0.00001$ \\
\hline $\mathrm{N}$ input ${ }^{2}$ & $-4.17 \mathrm{E}-05 \pm 5.1 \mathrm{E}-06$ & $-1.06 \pm 0.13$ & $<0.00001$ & $-2.8 \mathrm{E}-05 \pm 5.4 \mathrm{E}-06$ & $-1.42 \pm 0.27$ & $<0.00001$ \\
\hline Irrigation & $2.27 \pm 0.52$ & $2.07 \pm 0.47$ & 0.00003 & $-1.07 \pm 0.51$ & $-1.02 \pm 0.48$ & 0.037 \\
\hline $\mathrm{pH}$ & $0.29 \pm 0.20$ & $0.71 \pm 0.50$ & 0.15 & $-0.85 \pm 0.40$ & $-1.46 \pm 0.69$ & 0.038 \\
\hline Aridity & $1.13 \pm 0.51$ & $0.98 \pm 0.44$ & 0.03 & $-2.91 \pm 1.66$ & $-1.78 \pm 1.01$ & 0.09 \\
\hline Crop Type & $2.85 \pm 0.28$ & $2.79 \pm 0.28$ & $<0.00001$ & $1.00 \pm 0.18$ & $1.00 \pm 0.18$ & $<0.00001$ \\
\hline Latitude & $0.085 \pm 0.02$ & $2.72 \pm 0.49$ & $<0.00001$ & $0.03 \pm 0.08$ & $0.35 \pm 0.90$ & 0.70 \\
\hline Clay $(\%)$ & $0.041 \pm 0.01$ & $1.06 \pm 0.35$ & 0.003 & $-0.02 \pm 0.04$ & $-0.39 \pm 0.73$ & 0.59 \\
\hline SOC*N input & $0.002 \pm 0.0011$ & $0.70 \pm 0.26$ & 0.007 & $-7.6 \mathrm{E}-04 \pm 2.6 \mathrm{E}-03$ & $-0.14 \pm 0.48$ & 0.77 \\
\hline
\end{tabular}

As our data set contained a large number of observations from China $(n=353)$, we removed those

observations and re-ran our regression analysis $(n=481)$. The impact of $\mathrm{N}$ input on crop yield is similar to our original model, whereas the effect size of SOC is smaller. We also ran our regression model with only observations from China $(n=353)$. SOC had the largest coefficient, signifying a strong impact on crop yield. Observations from China had lower SOC contents overall with only 10 observations having more than $2 \%$ SOC and an average SOC concentration of $1.04 \%$.

Therefore, the large coefficient is capturing the steepest part of the SOM-productivity relationship (Fig. S3). This analysis demonstrates the need for regional analyses that capture the observed regional range of SOC values in order to quantify the relationship between SOM and productivity in a regionally-specific manner. 
Table S3: Modeled regression coefficients with standard errors, standardized

coefficients, and $\boldsymbol{P}$ values when including potential interactions between SOC and other explanatory variables.

\begin{tabular}{|c|c|c|c|}
\hline Variable & $\begin{array}{c}\text { Unstandardized } \\
\text { Coefficients }\end{array}$ & $\begin{array}{l}\text { Standardized } \\
\text { Coefficients }\end{array}$ & $P$ value \\
\hline Intercept & $-1.91 \pm 1.80$ & $5.48 \pm 0.19$ & $<0.00001$ \\
\hline SOC & $2.41 \pm 0.86$ & $1.44 \pm 0.30$ & $<0.00001$ \\
\hline $\mathrm{SOC}^{2}$ & $-0.63 \pm 0.21$ & $-0.91 \pm 0.30$ & 0.002 \\
\hline $\mathrm{N}$ input & $0.018 \pm 0.0014$ & $2.72 \pm 0.15$ & $<0.00001$ \\
\hline $\mathrm{N}$ input ${ }^{2}$ & $-3.83 \mathrm{E}-05 \pm 3.63 \mathrm{E}-06$ & $-1.62 \pm 0.15$ & $<0.00001$ \\
\hline Irrigation & $1.73 \pm 0.66$ & $0.69 \pm 0.45$ & 0.05 \\
\hline $\mathrm{pH}$ & $0.050 \pm 0.18$ & $0.12 \pm 0.43$ & 0.83 \\
\hline Aridity & $0.53 \pm 0.67$ & $-0.10 \pm 0.42$ & 0.82 \\
\hline Crop Type & $1.49 \pm 0.15$ & $1.49 \pm 0.15$ & $<0.00001$ \\
\hline Latitude & $0.058 \pm 0.016$ & $1.48 \pm 0.42$ & 0.001 \\
\hline Clay (\%) & $-0.02 \pm 0.024$ & $0.17 \pm 0.33$ & 0.60 \\
\hline $\mathrm{SOC}^{*} \mathrm{~N}$ input & $0.0041 \pm 0.0010$ & $1.00 \pm 0.25$ & $<0.00001$ \\
\hline SOC*Irrigation & $-0.92 \pm 0.50$ & $-1.10 \pm 0.59$ & 0.065 \\
\hline SOC:Clay & $0.022 \pm 0.015$ & $0.61 \pm 0.40$ & 0.13 \\
\hline SOC:Aridity & $-0.58 \pm 0.47$ & $-0.55 \pm 0.45$ & 0.22 \\
\hline
\end{tabular}

Regression results including additional interactions do not provide additional explanatory

power from our original model. The $r^{2}$ for the full model is 0.84 while the fixed effects explain $43 \%$ of the variation $(n=834)$. Furthermore, regression coefficients for SOC and $\mathrm{N}$ input are the same as from our original analysis. Therefore, we chose to focus solely on the SOC by N interaction included in our Results and Discussion. 
Table S4: Modeled regression coefficients with standard errors, standardized coefficients, and $\boldsymbol{P}$ values for our regression model when including phosphorus input.

\begin{tabular}{|c|c|c|c|}
\hline Variable & $\begin{array}{l}\text { Unstandardized } \\
\text { Coefficients }\end{array}$ & $\begin{array}{l}\text { Standardized } \\
\text { Coefficients }\end{array}$ & $P$ value \\
\hline Intercept & $-2.36 \pm 1.91$ & $5.62 \pm 0.21$ & $<0.00001$ \\
\hline SOC & $1.78 \pm 0.68$ & $1.48 \pm 0.35$ & 0.00002 \\
\hline $\mathrm{SOC}^{2}$ & $-0.42 \pm 0.21$ & $-0.60 \pm 0.30$ & 0.046 \\
\hline $\mathrm{N}$ input & $0.020 \pm 0.0017$ & $2.52 \pm 0.19$ & $<0.00001$ \\
\hline $\mathrm{N}$ input ${ }^{2}$ & $-0.0000471 \pm 4.71 \mathrm{E}-06$ & $-1.99 \pm 0.20$ & $<0.00001$ \\
\hline$P$ input & $0.0042 \pm 0.0021$ & $0.42 \pm 0.21$ & 0.045 \\
\hline Irrigation & $0.58 \pm 0.38$ & $0.58 \pm 0.38$ & 0.13 \\
\hline $\mathrm{pH}$ & $0.13 \pm 0.20$ & $0.30 \pm 0.47$ & 0.52 \\
\hline Aridity & $0.051 \pm 0.55$ & $0.040 \pm 0.43$ & 0.93 \\
\hline Crop Type & $1.56 \pm 0.16$ & $1.56 \pm 0.16$ & $<0.00001$ \\
\hline Clay (\%) & $0.019 \pm 0.016$ & $0.44 \pm 0.36$ & 0.23 \\
\hline Latitude & $0.055 \pm 0.019$ & $1.40 \pm 0.49$ & 0.005 \\
\hline SOC*N input & $0.0033 \pm 0.0011$ & $0.83 \pm 0.27$ & 0.0024 \\
\hline
\end{tabular}

Not all of our included studies contained specific rates of phosphorus input $(n=723)$;

however, we did carry out a regression that included P input. Standardized coefficients did not change significantly from our original model and so we chose not to include $\mathrm{P}$ input in our final model in order to include the greatest number of observations. 


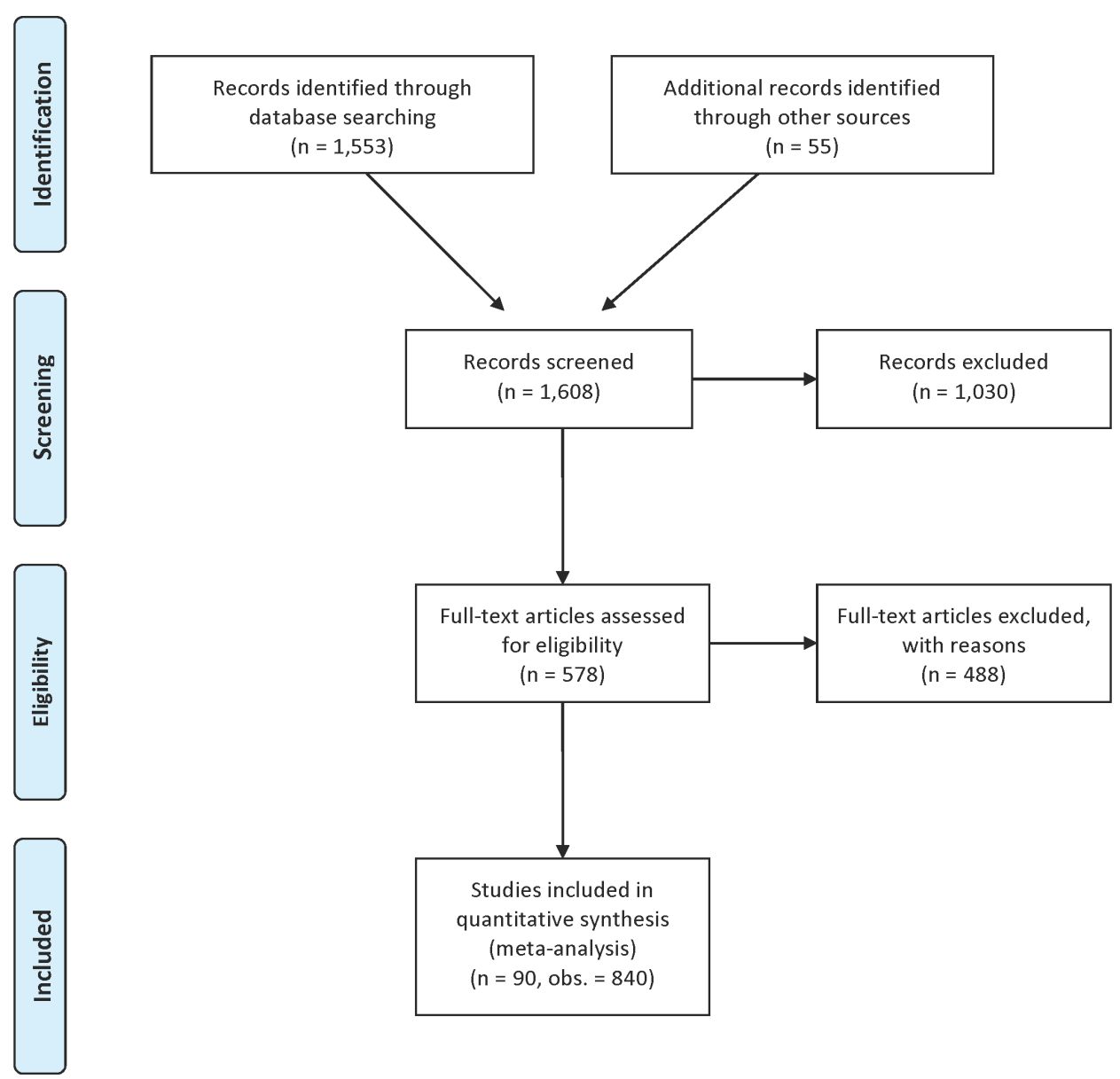

Figure S1: A PRISMA flow chart showing the identification, screening, eligibility, and inclusion process for all articles and observations. Our literature searches from Web of Science and the EviEM database resulted in 1,608 records considered during screening. The 1,030 articles rejected during the Screening stage were rejected because they focused on crops not included in our analysis and/or did not contain yield or SOC data. The 488 articles rejected during the Eligibility stage were rejected for any of the following reasons: They did not include paired experimental (as opposed to baseline) SOC-yield observations, they did not include bulk density data to convert SOC stocks to concentrations, or they did not include $\mathrm{N}$ fertilization rates. See Methods for further explanation. 

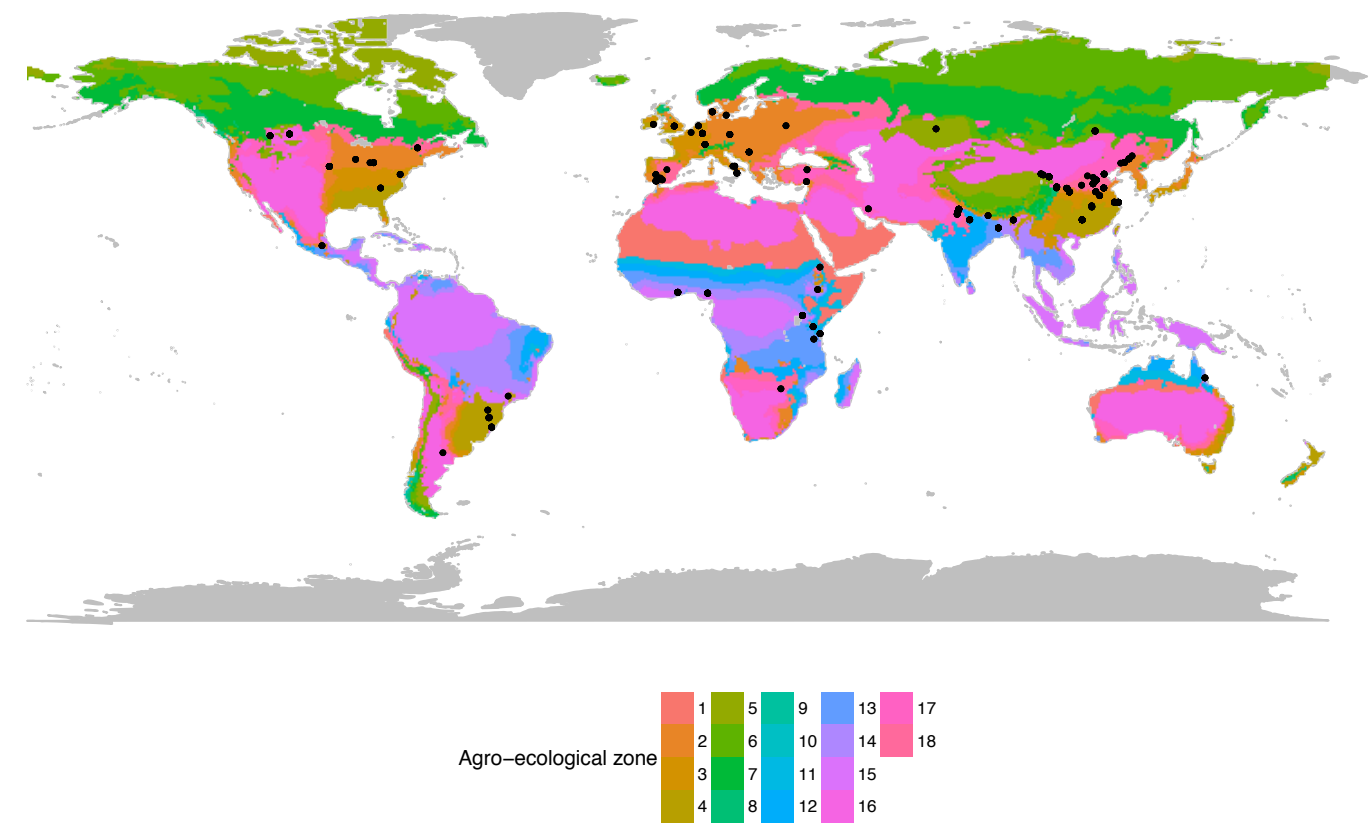

Figure S2: Global map of sites used to establish meta-data set within their respective agro-ecological zone (AEZ). Climate classifications for each AEZ are as follows: 1, tropical arid; 2, tropical-dry semi-arid; 3, tropical-moist, semi-arid; 4, tropical sub-humid; 5, tropical humid; 6 , tropical-humid (year round); 7, temperate arid; 8 , temperate-dry semi-arid; 9, temperate-moist semi-arid; 10, temperate sub-humid; 11, temperate humid; 12, temperate humid (year round); 13 , boreal arid; 14, boreal-dry semi-arid; 15 , borealmoist semi-arid; 16, boreal sub-humid; 17, boreal-humid; 18, boreal humid (year round). As our dataset contained observations primarily from the more humid AEZs, future research should prioritize research in the more arid AEZs, particularly AEZ 2 (tropicaldry semi-arid) and AEZ 3 (tropical-moist semi-arid). 
a)

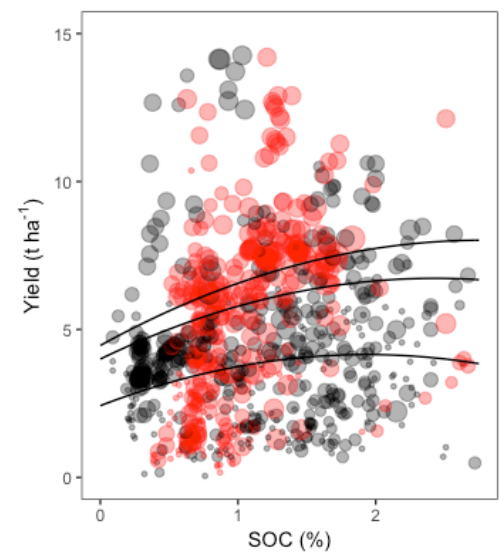

b)

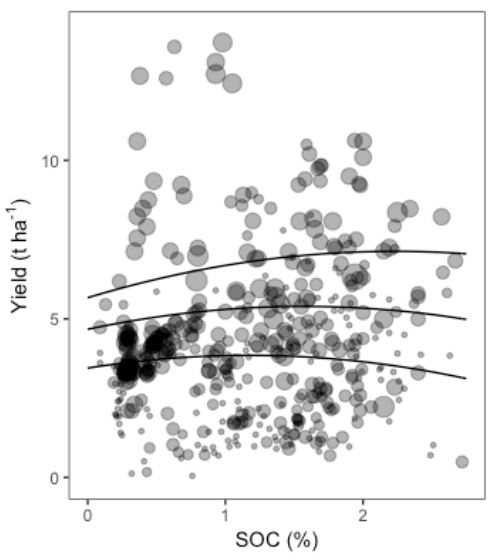

c)

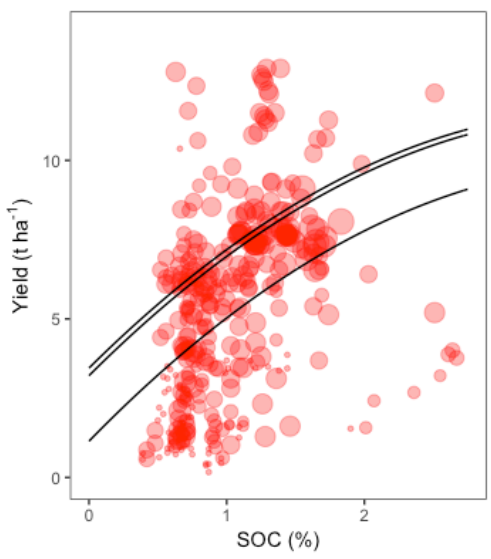

Figure S3: Relationship between SOC and yield of maize for different subsets of

data. The regression lines are modeled yields (i.e. effect sizes) for rain-fed maize for (a) the entire dataset with Chinese observations colored in red, (b) the dataset excluding observations from China, and (c) the dataset including only observations from China. All graphs include modeled yields at three different rates of $\mathrm{N}$ input: $0 \mathrm{~kg} \mathrm{~N}^{-1}$, the average $\mathrm{N}$ input for the given subset of data $\left(120,75\right.$, and $165 \mathrm{~kg} \mathrm{~N} \mathrm{ha}^{-1}$, respectively), and $200 \mathrm{~kg}$ $\mathrm{N} \mathrm{ha}^{-1}$. The effect size of SOC changes depending on the subset of data explored. For instance, the effect size of SOC for Chinese-only observations (panel c) was the largest; however, this subset of data has only 10 data points with SOC levels above $2 \%$ (see $\mathrm{x}$ axis above) and so captures the steepest part of the SOC-yield relationship as pictured in (a). Regression lines within each graph are modeled using observed means for each subset of data for aridity, $\mathrm{pH}$, texture, and latitude. Regression output for each subset of data is included in Table S2. 

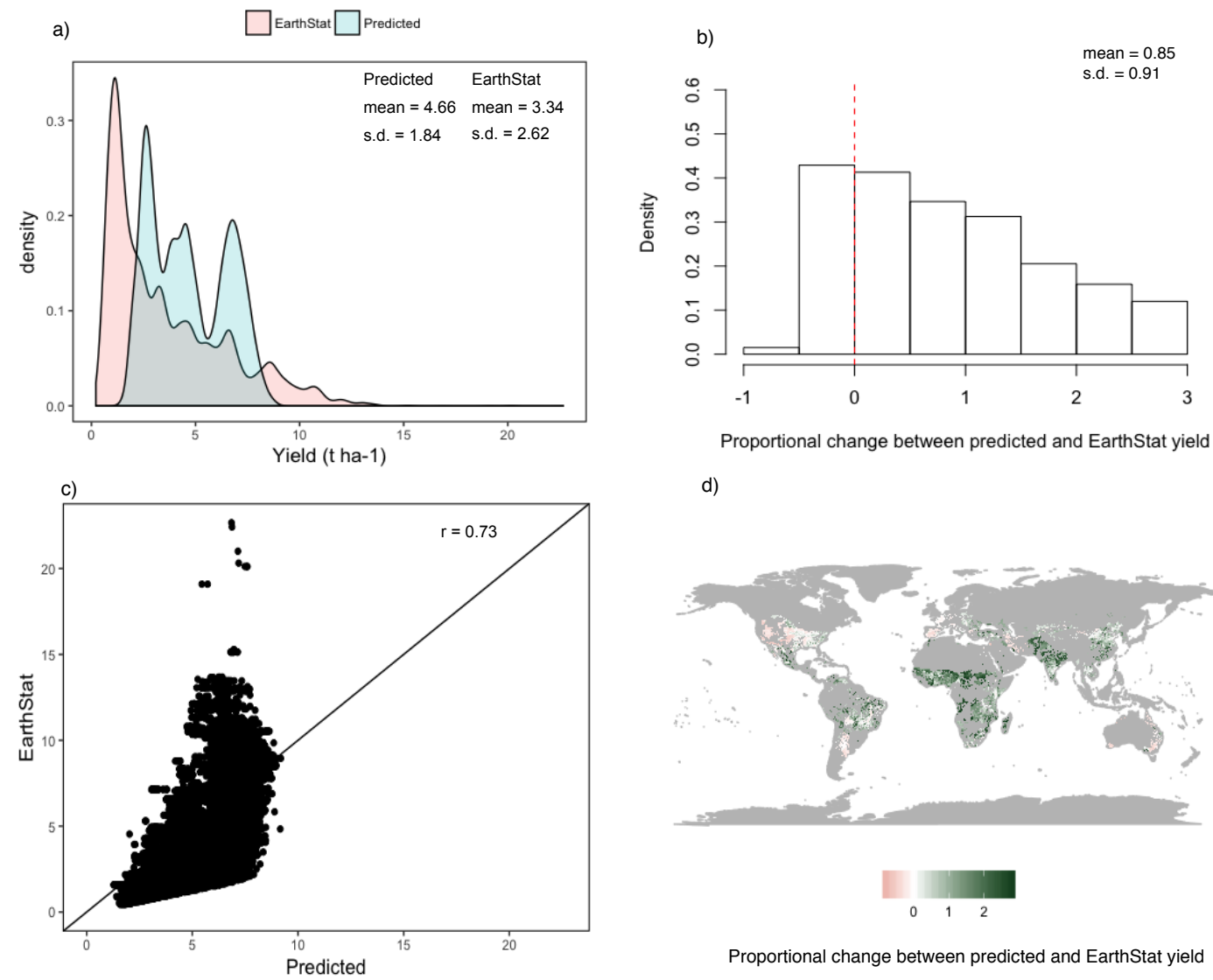

d)

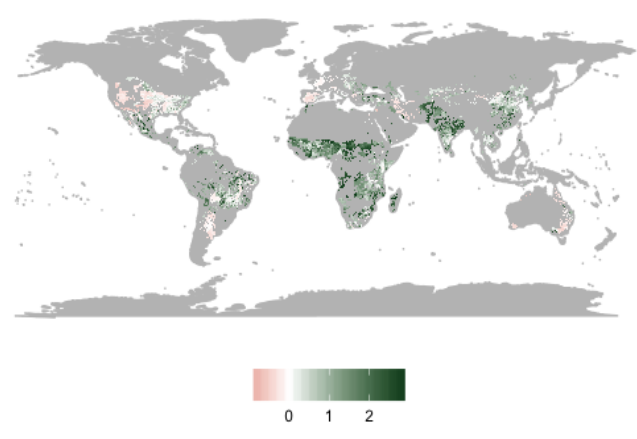

Proportional change between predicted and EarthStat yield

Figure S4: Data quality analysis for EarthStat and modeled maize yields. To ensure global extrapolations based on our regression model were adequate, we performed a number of data checks. (a) Mapped distributions of both predicted global maize yields, calculated by our regression model, and EarthStat global maize yields. (b) Histogram of the proportional change between predicted maize yields and EarthStat yields. (c) A 1:1 plot of predicted maize yields versus EarthStat maize yields. (d) A global map of the proportional change between predicted and EarthStat maize yields. We dropped all cells for which the proportional difference between predicted and gridded data was $>3$-times. This threshold represents the mean \pm half the standard deviation for the distribution of the proportional difference between predicted and EarthStat yield data. Overall, $86 \%$ of maize values fall within this range, and there was a relatively strong correlation $(\mathrm{r}=0.73)$ between EarthStat and predicted yields, lending credence to our global extrapolations. 

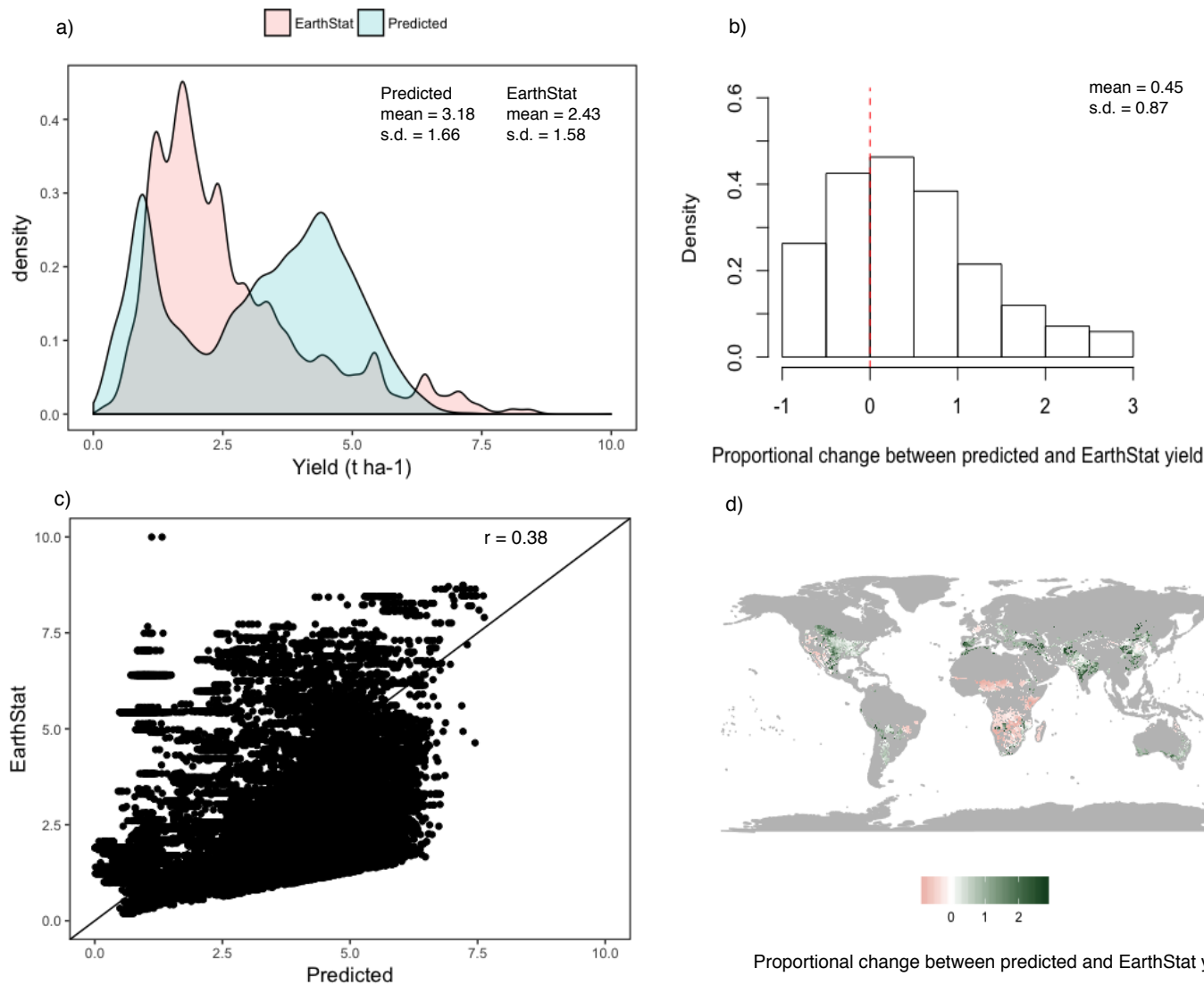

Proportional change between predicted and EarthStat yield

d)

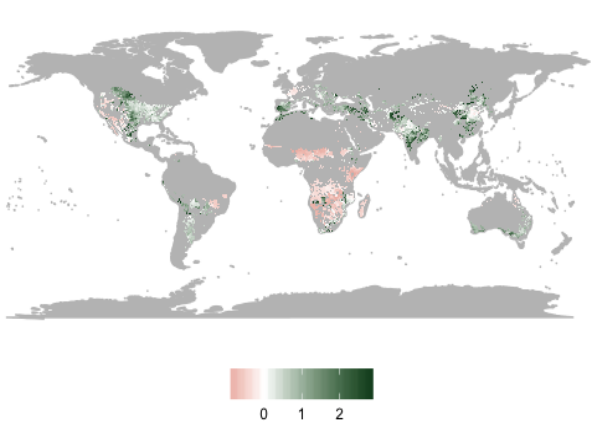

Proportional change between predicted and EarthStat yield

Figure S5: Data quality analysis for EarthStat and modeled wheat yields. The same data checks were applied to predicted and EarthStat wheat yields as in S2 Fig. (a) Mapped distributions of both predicted global wheat yields, calculated by our regression model, and EarthStat global wheat yields. (b) Histogram of the proportional change between predicted wheat yields and EarthStat yields. (c) A 1:1 plot of predicted wheat yields versus EarthStat wheat yields. (d) A global map of the proportional change between predicted and EarthStat wheat yields. For wheat data quality, 93\% of modelpredicted wheat yields fell within the mean \pm half the standard deviation for the distribution of the proportional difference between predicted and EarthStat yield data (i.e. the proportional difference between predicted and gridded data was $<3$-times) and the correlation coefficient was 0.38 . 